\title{
PENGARUH BUDAYA ORGANISASI DAN BESARNYA KOMPENSASI TERHADAP KEPUASAN KERJA KARYAWAN RUMAH SAKIT KARYA MEDIKA
}

\author{
Nurdin \\ Universitas Indraprasta PGRI \\ Nur.albaniah@ymail.com \\ Hp 081399968520
}

\begin{abstract}
This study aims to determine influence the organizations culture and the amount of compensation to employees satisfaction. The study population were employees of numbered 50 people. 30 samples are taken randomly. Cultural organizations give significant influence on employees job satisfaction. The data processing value $\mathrm{t}=4.271>5 \%=2,045$. $\alpha \mathrm{t}$ table value at The amount of compensation gives significant influence on employees job satisfaction. Data processing results obtained by value $\mathrm{t}=$ 5.143> $5 \%=2,045 . \alpha t$ table value at Organizations culture and magnitude of compensation together give a significant effect on employees job satisfaction. The data processing coefficient of determination (R2) of $87.2 \%$ means that increase employees job satisfaction is influenced by the culture of the organizations and the amount of compensation, while the remaining $12.8 \%(100 \%$ $87, \%)$ affected by other factors that were not analyzed.
\end{abstract}

Keywords: Culture, compensation, job satisfaction

\begin{abstract}
ABSTRAK
Penelitian ini bertujuan untuk mengetahui pengaruh budaya organisasi dan besarnya kompensasi terhadap kepuasan kerja karyawan. Populasi penelitian adalah karyawan berjumlah 50 orang. Sampel penelitian sebanyak 30 orang diambil secara acak. Budaya organisasi memberi pengaruh yang signifikan terhadap kepuasan kerja karyawan. Hasil pengolahan data nilai $t_{\text {hitung }}=4,271>$ nilai $t_{\text {tabel }}$ pada $\alpha 5 \%=2,045$. Besarnya kompensasi memberi pengaruh yang signifikan terhadap kepuasan kerja karyawan. Hasil pengolahan data diperoleh nilai $t_{\text {hitung }}=5,143>$ nilai $t_{\text {tabel }}$ pada $\alpha 5 \%=2,045$. Budaya organisasi dan besarnya kompensasi secara bersama-sama memberi pengaruh yang signifikan terhadap kepuasan kerja karyawan. Hasil pengolahan data nilai koefisien determinasi $\left(\mathrm{R}^{2}\right)$ sebesar $87,2 \%$ artinya peningkatan kepuasan kerja karyawan dipengaruhi oleh budaya organisasi dan besarnya kompensasi, sedangkan sisanya 12,8\% (100\% - 87,\%) dipengaruhi oleh faktor lainnya yang tidak dianalisis.
\end{abstract}

Kata Kunci : Budaya, kompensasi, kepuasan kerja 


\section{PENDAHULUAN}

Setiap perusahaan menginginkan kinerja karyawan lebih baik. Untuk mencapai kinerja tersebut, pimpinan mengerti kebutuhan karyawan, sehingga karyawan merasa puas dan selalu berusaha untuk meningkatkan kinerjanya. Karyawan yang tidak pernah mencapai suatu kepuasan pada akhirnya akan menjadi frustasi. Hal itu mengakibatkan perusahaan menjadi rugi. Karyawan seperti ini semangat kerjanya kurang, cepat lelah, bosan, malas bekerja, sehingga tugasnya tidak akan selesai tepat pada waktunya. Hal itu kepuasan bagi setiap karyawan perlu diperhatikan, sebab berkaitan dengan tujuan manusia mengaktualisasikan potensi dirinya dalam suatu pekerjaan. Bekerja memiliki arti melaksanakan suatu tugas yang diakhiri dengan hasil kerja yang dapat dinikmati oleh manusia. Karyawan dan perusahaan merupakan dua hal yang tidak bisa dipisahkan, sebab karyawan memegang peranan yang sangat penting untuk meningkatkan keuntungan perusahaan. Untuk itu, perusahaan perlu memperhatikan kepuasan karyawannya. Dengan demikian, salah satu tugas manajemen adalah perlu menyesuaikan keinginan karyawan sehingga karyawan tidak cepat bosan dalam melaksanakan tugasnya.

Untuk dapat meingkatkan kinerja karyawan, beberapa faktor yang perlu diperhatikan oleh seorang pemimpin, yaitu gaji yang diterima karyawan sesuai dengan pekerjaannya, penghargaan bagi karyawan yang mempunyai prestasi baik, bonus yang diterima sesuai dengan prestasinya, tunjangan kesehatan, tunjangan kesejahteraan, promosi jabatan bagi karyawan yang berprestasi,teman kerja yang menyenangkan, kesempatan untuk maju, kondisi kerja yang nyaman, aman dan menarik, kepemimpinan yang mampu dan adil, perintah yang masuk akal, serta organisasi yang sehat.

\section{Berdasarkan kondisi perusahaan,} rumusan masalah (1) Apakah budaya organisasi dapat memberi pengaruh yang signifikan terhadap kepuasan kerja karyawan, (2) Apakah besarnya kompensasi dapat memberi pengaruh yang signifikan terhadap kepuasan kerja karyawan, dan (3) Apakah budaya organisasi dan besarnya kompensasi secara bersama- sama dapat memberi pengaruh yang signifikan terhadap kepuasan kerja karyawan.

adalah
Menurut Kotler (1994; 65) kepuasan perasaan senang terhadap jasa yang diperoleh karyawan setelah melaksanakan tugasnya. Jadi, dapat dikatakan bahwa faktor utama untuk mempengaruhi kepuasan seorang karyawan adalah gaji yang meraka terima. Menurut Martoyo (1990; 54) kepuasan merupakan keadaan emosional karyawan karena terjadi kesesuaian balas jasa yang diinginkan dari suatu perusahaan, sedangkan Handoko (2001; 87) menyatakan kepuasan kerja adalah keadaan emosional yang menyenangkan atau tidak menyenangkan dengan nama para kaaryawan memandang pekerjaan mereka.

Mengenai kerja, Stoner dan Freeman (2000; 13) menyatakan bahwa kerja adalah melakukan sesuatu dengan benar. Dalam, hal ini, bekerja diharapkan dapat menghasilkan sesuatu dengan baik sesuai dengan tujuan yang dikehendaki. Tinggi rendahnya kinerja karyawan berhubungan erat dengan pemberian penghargaan yang diterapkan oleh suatu organisasi. Menurut Suprihanto (2000; 7) menyebutkan bahwa kinerja yaitu hasil kerja seseorang selama periode tertentu dibandingkan dengan berbagai kemungkinan misalnya standar dan sasaran. Seseorang dapat dikatakan bekerja dengan baik bila bekerja dengan efektif, yang menunjuk kepada terlaksananya suatu tugas yang sesuai persyaratan yang dikehendaki. Menurut Koontz (Winardi, 2000; 8) menyatakan bahwa pencapaian suatu tujuan adalah pemenuhan kriteria atas suatu produk yang dihasilkan. Pemenuhan kriteria ini, antara lain dapat dilihat dari segi peralatan, metode, skill dan teknologi yang digunakan. Dari segi peralatan, yang perlu diperhatikan apakah peralatan yang digunakan dapat memproduksi produk yang diinginkan, metode atau langkahlangkah kerja (prosedur) yang digunakan demi terlaksananya proses yang tepat, apakah tersedia prosedur kerja baku yang tetap. Skill menunjukkan kepada kemampuan karyawan untuk menggunakan alat dan melaksanakan tugas dengan benar. Teknologi menunjukkan kepada kemudahan dan keanekaragaman kemudahan yang tersedia. Menurut Suprihanto (2000; 5) bekerja adalah derajad pencapaian tujuan,dalam hal ini tingkat penggunaan potensi diri seseorang dibandingkan dengan kapasitas diri seseorang tersebut. Artinya pegawai berusaha dengan baik untuk menggunakan kemampuannya dalammelaksanakan tugas demi tercapainya tujuan yang telah ditetapkan perusahaan. 
Menurut Whitmore (2000; 106) kinerja adala melaksanaan fungsi-fungsi yang diberikan dari seseorang. Menurut Cushway (2002; 1998) kinerja adalah menilai bagaimana seseorang telah bekerja dibandingkan dengan target yang telah ditentukan. Selanjutnya dikemukakan bahawa kinerja adalah merupakan perilaku nyata yang ditampilkan setiap orang sebagai prestasi kerja yang dihasilkan oleh karyawan sesuai dengan perannya dalam perusahaan. Prawirosentoso $(2001 ; 69)$ berpendapat bahwa performance adalah hasil kerja yang dapat dicapai oleh seseorang atau sekelompok orang dalam suatu organisasi sesuai dengan wewenang dan tanggung jawab masing-masing dalam rangka mencapai tujuan organisasi, tidak melanggar hukum dan sesuai dengan etika. As'ad (2002; 37) menyatakan kinerja adalah keberhasilan seseorang dalam melaksanakan suatu pekerjaan.

Berdasarkan uraian diatas, penulis dapat menyimpulkan bahwa kepuasan kerja karyawan adalah kepuasan seorang karyawan terhadap gaji yang diterima setelah melaksanan tugasnya dengan baik.

\section{Budaya Organisasi}

Menurut Shein $(1985 ; 87)$ budaya adalah suatu pola dari asumsi dasar yang ditemukan dan dikembangkan oleh suatu kelompok tertentu dari organisasi, kemudian menjadi acuan dalam menghadapi persoalan yang berkaitan dengan adaptasi, baik keluar maupun integrasi internal. Menurut Koentjaraningrat (2002; 75) budaya adalah seluruh total dari pikiran, hasil karya manusia yang tidak berakhir pada nalurinya, dan hanya bisa dicetuskan oleh manusia sesudah proses belajar. Menurut pendapat Neale and Norteraf (1998; 43) budaya adalah suatu kebiasaan yang dilakukan untuk menunjang kegiatan perusahaan. Menurut Luthans (1995; 75) budaya organisasi dipengaruhi oleh faktor, yaitu (1) pengarauh umum adalah faktor yanag sulit dikendalikan dan hanya sedikit dapat dikendalikan oleh organisasi, dan (2) faktor spesifik dari organisasi adalah organisasi selalu berinteraksi dengan lingkungannya. Hal tersebut mengandung makna bahwa manusia selalu berusaha untuk menyelesaikan persoalan yang timbul di dalan suatu organisasi, baik persoalan internal maupun persoalan eksternal.

Mengenai organisasi, menurut Muhlis $(2000 ; 32)$ adalah perpaduan secara sistimatis dari bagian - bagian yang saling ketergantungan untuk membentuk suatu kesatuan yang bulat melalui kewenangan, dan pengawasan dalam usaha mencapai tujuan yang telah ditentukan. Selanjutnya dikatakan organisasi adalah setiap bentuk kerja sama untuk mencapai tujuan bersama. Lebih lanjut dikatakan prinsip-prinsip suatu organisasi sebagai berikut : (1) mempunyai tujuan yang jelas, (2) skala hierarki, (3) pendelegasian wewenang, (4) pembagian pekerjaan, (5) rentang pengendalian, (6) pertanggung jawaban, dan (7) fungsional, sedangkan menurut Robbins (2001; 18) organisasi mempunyai ciri-ciri sepeerti: (1) karyawan didukung untuk menjadi inovatif dan mengambil resiko, (2) suatu identitas bagi anggota organisasi, (3) timbulnya komitmen pada sesuatu yang lebih luas dari pada kepentingan individu, (4) pembuat makna dan kendali untuk membentuk sikap dan perilaku karyawan, (6) manajeman mempokuskan pada suatu tujuan.

Tan and Viktor $(2002 ; 8)$ mengemukakan budaya organisasi adalah cara seseorang melakukan sesuatu dalam organisasi, budaya organisasi merupakan satuan norma yang terdiri dari keyakinan, sikap, dan pola perilaku yang dilakukan oleh seseorang. Menurut Siagian (2002; 188) budaya organisasi adalah kemauan, kemampuan, dan kesediaan seseorang menyesuaikan perilakunya dengan budaya kerja, mempunyai relevansi dengan kemauan, kemampuan, dan kesediaanya meningkatkan produktivitas kerjanya. Wibowo (2006; 347) menyebutkan budaya organisasi adalah normanorma dan kebiasaan yang diterima sebagai suatu kebenaran oleh semua orang dalam organisasi. Budaya suatu organisasi adalah karakteristik semangat dan kepecayaan yang diperlihatkan orang-orang didalamnya (Tan; 8). Menurut Newstron dan Davis (1993; 58) budaya organisasi adalah kumpulan asumsi, kepercayaan, nilai dan norma-norma yang menjadi bagian diantara anggotanya. Menurut Randolph dan Blackkburn (1989; 64) budaya organisasi diartikan sebagai kumpulan dari nilai-nilai kepercayaan, dan pemahaman yang diberikan oleh anggota dari suatu organisasi. Menurut Luthans and Freed (1995; 98) budaya organisasi adalah suatu persepsi bersama yang dipegang oleh anggota organisasi. Menurut Wibowo $(2006$; 61) budaya organisasi adalah bagian sikap dan persepsi di dalam suatu organisasi yang didasarkan pada sekumpulan 
norma dan nilai-nilai dasar dan membantu anggota untuk memahami organisasi.

Morhead and Griffin (1999; 513) menyatakan budaya organisasi adalah kumpulan nilai-nilai yang membantu karayawan disuatu organisasi untuk memahami tindakan mana yang dapat diperrtimbankan untuk diterima dan mana yang tidak diterima. Menurut Mondy dan Premeaux (1993; 455) ada tiga klasifikasi budaya yaitu: (1) budaya dominan, (2) sub budaya, dan (3) budaya kuat. Budaya dominan mengungkapkan nilai-nilai yang dianut oleh mayoritas anggota organisasi, budaya dominan merupakan kepribadian organisasi secara keseluruhan yang membedakannya dengan organisasi lain. Budaya dominan merupakan panduan perilaku karyawan sehari-hari dalam melaksanakan pekerjaannya karena merupakan kepribadian organisasi. Sub budaya merupakan budaya di dalam suatu organisasi yang lazim ditentukan oleh rambu-rambu organisasi misalnya bagian pemasaran memiliki sub budaya yang secara unik dianut bersama oleh anggota dari bagian tersebut. Sub budaya cenderung berkembang dalam organisasi besar untuk mencerminkan masalah, situasi, dan pengalaman bersama yang dihadapi para anggotanya. Sub budaya dapat juga merupakan kepribadian dari masingmasing bagian organisasi. Namun di sisi lain sub budaya ini dapat juga memperlemah atau menganggu organisasi terutama jika terjadi konflik antara budaya yang dominan atau tujuan organisasi secara keseluruhan dengan sub budaya yang ada. Budaya kuat merupakan inti organisasi dipegang secara intensif dan dianut bersama secara meluas. Makin banyak anggota yang menerima nilai inti dan makin besar komitmen mereka pada nilai-nilai tersebut, budaya kuat juga menggambarkan kesepakatan yang tinggi di kalangan anggota organisasi mengenai apa yang dipertahankan oleh organisasi.

Berdasarkan uraian, penulis dapat simpulkan bahwa budaya organisasi adalah suatu norma yang terdiri dari keyakinan, sikap, dan perilaku karyawan untuk membentuk suatu kesatuan yang baik supaya tujuan organisasi tercapai.

\section{Besarnya kompensasi}

Desler dan Garry $(2000 ; 89)$ menyatakan kompensasi adalah setiap bentuk pembayaran yang diberikan kepada karyawan yang telah melaksanakan tugasnya. Selanjutnya dikatakan kompensasi karyawan mempunyai 2 (dua) komponen, yaitu (1) pembayaran langsung dalam bentuk upah, gaji, komisi, dan bonus, dan (2) pembayaran tidak langsung dalam bentuk tunjangan, seperti asuransi dan uang liburan yang dibayarkan perusahaan. Menurut Muhlis $(2002$; 7) gaji diartikan sebagai pembayaran pokok yang diterima oleh seseorang, tidak termasuk unsur-unsur variabel dan tunjangan lainnya. Dewan penelitian pengupahan nasional (Husnan, 2000; 142) mendefinisikan bahwa upah adalah suatu penerimaan sebagai suatu imbalan dari pemberi kerja kepada penerima kerja untuk suatu pekerjaan yang telah dilakukan berfungsi sebagai jaminan kelangsungan kehidupan yang layak bagi kemanusiaan dan produksi. Upah dinilai dalam bentuk uang yang ditetapkan menurut suatu persetujuan, undang-undang dan peraturan serta dibayarkan atas dasar suatu perjanjian kerja antara pemberi kerja dan penerima kerja.

Flippo (2000; 75-76) mengatakan bahwa kompensasi adalah jasa yang diterima karyawan setelah melaksanakan tugasnya. Menurut Desler dan Garry (2000; 89) untuk menentukan gaji ada beberapa faktor yang mempengaruhi yaitu: (1) faktor hukum, dalam faktor ini besarnya gaji yang harus dibayar diatur dalam undang-undang meliputi gaji minimum, tarif lembur, dan tunjangan, (2) faktor serikat buruh, diatur dalam Undangundang mengenai hubungan tenaga kerja yaitu adanya tawar menawar antara serikat buruh dengan yang mempekerjakan, (3) faktor kebijakan, pemberian kompensasi mempengaruhi upah yang dibayar, kebijakan ini mempengaruhi tingkat upah dan tunjangan misalnya perbedaan gaji bagi karyawan yang masih dalam masa percobaan, dan (4) faktor keadilan, sangat penting dalam menentukan tinggi rendahnya pembayaran gaji dalam arti bahwa keadilan eksternal tarif gaji harus sebanding dengan organisasi lain, sedangkan keadilan internal hendaknya setiap karyawan memperoleh pembayaran gaji sesuai lamanya seseorang dalam melaksanakan tugasnya.

Proses penetapan tarif upah diharapkan dapat menjamin keadilan eksternal dan internal menempuh 5 ((lima) langkah yaitu : (1) lakukan survey mengenai gaji tentang pembayaran dari organisasi lain, (2) tentukanlah nilai dari masing-masing pekerjaan dalam organisasi melalui evaluasi jabatan. (3) kelompokkan pekerjaan-pekerjaan serupa 
kedalam tingkat upah. (4) tetapkan harga masing-masing tingkat pembayaran dengan menggunakan kurva upah, dan (5) tentukan dengan tepat taraif upah . Teori keadilan menurut Gibson and Donnelly $(2000 ; 158)$ menyatakan keadilan (equit) adalah suatu keadaan yang muncul dalam pikiran seseorang jika ia merasa bahwa ratio antara usaha dan imbalan seimbang. Inti dari teori keadailan ialah bahwa karyawan membandingkan usaha mereka terhadap imbalan dengan imbalan karyawan lainnya dalam situasi kerja yang sama. Teori tersebut didasarkan pada asumsi bahwa karyawan dimotivasi oleh keinginan untuk diperlukan secara adil dalam pekerjaan. Karyawan bekerja untuk mendapatkan imbalaan dari organisasi. Menurut Muhlis (2002; 20-25) untuk mencapai suatu pekerjaan perlu dilakukan beberapa langkah sebagai berikut: (1) menganalisis keadaan sekarang yaitu meliputi analisis berbagai jabatan, banyaknya staf dalam setiap jabatan, besarnya gaji, (2) merumuskan kebijakan yaitu penggajian ditetapkan oleh pimpinan yang bertanggung jawab, (3) menilai pekerjaan yaitu dengan menggunakan teknik penilaian pekerjaan dari berbagai aspek, (4) merencanakan struktur gaji yaitu struktur gaji harus mencerminkan hubungan pekerjaan, (5) mengembangkan prosedur sistem penggajian yaitu untuk menjamin kebijakan dan anggaran dilaksanakan dengan baik, kenaikan gaji dihubungkan dengan prestasi, dan (6) merencanakan seluruh aspek balas jasa yaitu penetapan gaji pokok dan unsur tunjangan, lembur, bonus, dan pembagian laba yang diperoleh perusahaan.

Berdasarkan uraian, penulis dapat simpulkan bahwa besarnya kompensasi adalah besarnya gaji yang diterima karyawan setelah melaksanakan tugasnya dengan baik.

\section{METODE PENELITIAN}

Penelitian ini menggunakan metode korelasi, yaitu dapat melihat besarnya pengaruh budaya organisasi dan besarnya kompensasi terhadap kepuasan kerja karyawan. Penelitian dilaksanakan selama 2 bulan yaitu, dari April sampai dengan Juni 2017. Populasi penelitian adalah karyawan rumah sakit karya medika sebanyak 50 orang. Sampel penelitian sebanyak 30 orang diambil secara acak (simple random sampling)
Gambar 1. Konstalasi Penelitian

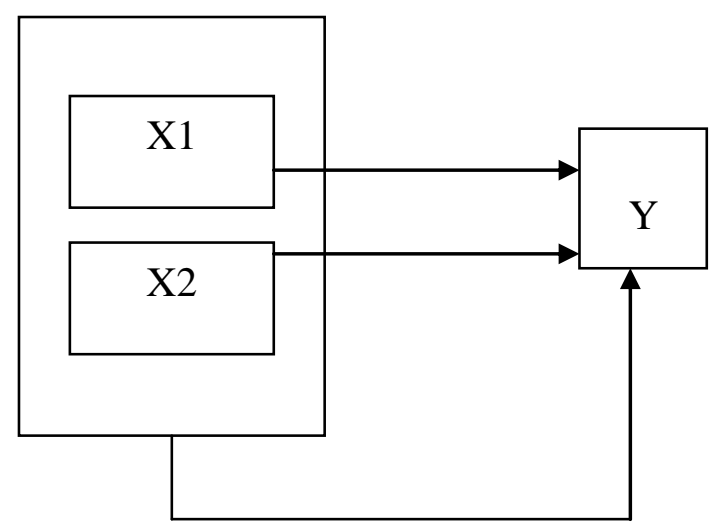

Keterangan :

$\mathrm{Y}=$ Kepuasan kerja karyawan rumah sakit karya medika

$\mathrm{X} 1$ = Budaya organisasi

$\mathrm{X} 2=$ Pemberian kompensasi

\section{Pengujian Validitas}

Untuk menguji validitas dicari korelasi dari setiap butir pertanyaan dengan skor ratarata totalnya dengan bantuan software spss versi 22,00. Pengukuran validitas dengan rumus korelasi product moment (pearson correlation).

\section{Pengujian Reliabilitas}

Untuk menguji reliabilitas dari setiap konstrak menggunakan metode cronbach' s Alpha dengan bantuan SPSS versi 22.0.

\section{Teknik Analisis Data}

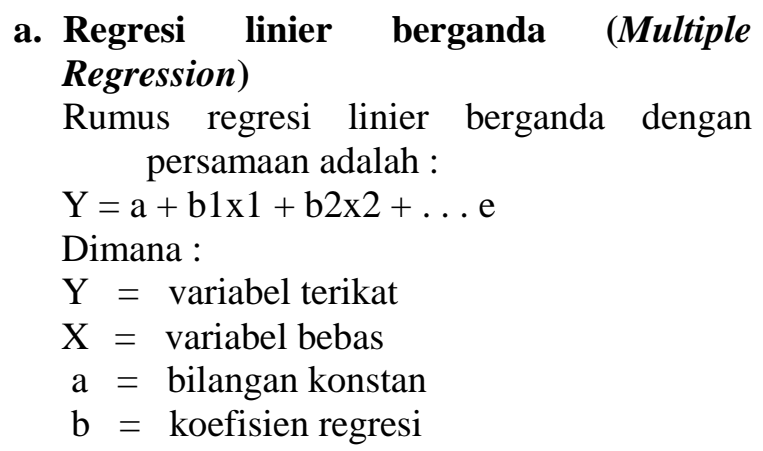

Untuk mencari nilai a dan nilai $b$ digunakan rumus berikut :

$$
a=\frac{\left(\sum Y-b \sum X\right)}{n}
$$




$$
b=\frac{n \sum X Y-\sum X \sum Y}{n \sum X^{2}-\left(\sum X\right)^{2}}
$$

\section{b. Koefisien korelasi}

Untuk mengetahui erat atau tidaknya pengaruh variabel bebas terhadap variabel terikat digunakan rumus berikut :

$$
\begin{aligned}
r= & \frac{n \sum X Y-\sum X \sum Y}{\sqrt{n \sum X^{2}-\left(\sum X\right)^{2}} \cdot \sqrt{n \sum X^{2}-\left(\sum X\right)^{2}}} \\
r & =\text { koefisien korelasi } \\
\mathrm{n} & =\text { jumlah sampel } \\
\mathrm{x} & =\text { variabel bebas }
\end{aligned}
$$

\section{c. Uji T (Parsial)}

Untuk melihat signifikan pengaruh masing-masing variabel bebas terhadap variabel terikat digunakan alpha 5\% dengan ketentuan sebagai berikut :

1) Jika $t_{\text {-hitung }}>\mathrm{t}_{\text {-tabel, }}$ maka $\mathrm{H}_{1}$ diterima.

2) Jika t-hitung $<t_{-}$tabel, maka $\mathrm{H}_{1}$ diterima.

d. Uji F (Signifikan)

Untuk menguji pengaruh variabel bebas secara bersama-sama terhadap variabel terikat digunakan alpha 5\% dengan ketentuan sebaga berikut:

1) Jika $F_{\text {hitung }}>F_{\text {tabel }}$ maka $\mathrm{H}_{1}$ diterima.

2) Jika $F_{\text {hitung }}>F_{\text {tabel }}$ maka $H_{1}$ diterima.

\section{e. Koefisien determinasi}

Koefisien determinasi dilakukan untuk mengukur seberapa besar hubungan variabel bebas terhadap variabel terikat. Besarnya nilai $R^{2}$ adalah antara 0 sampai 1 dengan rumus :

$\mathrm{R}^{2}=(\mathrm{r})^{2} \times 100 \%$ Dimana :

\begin{tabular}{|c|c|c|c|c|c|c|c|c|}
\hline \multirow[b]{2}{*}{ Model } & & \multicolumn{2}{|c|}{$\begin{array}{l}\text { Unstandardized } \\
\text { Coefficients }\end{array}$} & \multirow[t]{2}{*}{$\begin{array}{l}\text { Standardized } \\
\text { Coefficients }\end{array}$} & \multirow[b]{2}{*}{$\mathrm{t}$} & \multirow[b]{2}{*}{ Sig. } & \multicolumn{2}{|c|}{$\begin{array}{l}\text { Collinearity } \\
\text { Statistics }\end{array}$} \\
\hline & & $\mathrm{B}$ & Std. Error & & & & & \\
\hline \multirow{3}{*}{1} & (Constant) & .643 & .275 & & 3.982 & .007 & & \\
\hline & B. organis & .457 & .379 & .427 & 4.271 & .001 & 435 & 1,726 \\
\hline & B. Komp & .513 & .398 & .518 & 5,143 & 003 & .372 & 1,436 \\
\hline
\end{tabular}

$\mathrm{R}^{2}=$ koefisien determinasi

$\mathrm{r}=$ koefisien korelasi

\section{HASIL DAN PEMBAHASAN}

Coefficients $^{a}$

a. Depent Variable: Kinerja karyawan

\section{Persamaan regresi :}

$$
\begin{aligned}
\mathrm{Y} & =\mathrm{a}+\mathrm{b}_{1} \mathrm{x}_{1}+\mathrm{b}_{2} \mathrm{x}_{2}+\ldots \mathrm{e} \\
& =0,643+0,457+0,513
\end{aligned}
$$

Dengan menggunakan analisa regresi berganda, maka diperoleh persamaan sebagai berikut : Konstanta sebesar 0,643 dinyatakan bahwa budaya organisasi dan besarnya kompensasi konstant (tetap) maka kepuasan kerja karyawan adalah 0,643

\section{Uji T (Parsial)}

a. Koefisien regresi budaya organisasi sebesar 4,271 menunjukkan bahwa pengaruh budaya organisasi terhadap kepuasan kerja karyawan adalah positif. Berdasarkan nilai koefisien regresi dinyatakan bahwa budaya organisasi memberi pengaruh yang signifikan terhadap kepuasan kerja karyawan pada $\alpha 5 \%=2,132$

b. Koefisien regresi besarnya konpensasi sebesar 5,143 menunjukkan bahwa pengaruh besarnya konpensasi terhadap kepuasan kerja karyawan adalah positif. Berdasarkan nilai koefisien regresi dinyatakan bahwa besarnya konpensasi memberi pengaruh yang signifikan terhadap kepuasan kerja karyawan pada $\alpha 5 \%=2,132$

\section{Uji F (Signifikan)}




\section{ANOVA $^{\mathrm{a}}$}

\begin{tabular}{llrrrrr}
\hline Model & & \multicolumn{6}{c}{$\begin{array}{c}\text { Sum of } \\
\text { Squares }\end{array}$} & df & $\begin{array}{c}\text { Mean } \\
\text { Square }\end{array}$ & F & Sig. \\
\hline \multirow{3}{*}{1} & Regression & 4,635 & 3 & 1,347 & 3,572 & $002^{\mathrm{b}}$ \\
\cline { 2 - 7 } & Residual & 3,622 & 53 & 0,52 & & \\
\cline { 2 - 7 } & Total & 4,981 & 41 & & & \\
\hline
\end{tabular}

a. Predictor (Constant) : Budaya organisai

b. Dependent Variable : Nesarnya Kompensasi

Budaya organisasi dan besarnya konpensasi secara bersama-sama memberi pengaruh yang signifikan terhadap kepuasan

kerja karyawan dengan nilai $t_{\text {hitung }}$ sebesar 3,572

$>t_{\text {tabel }}$ pada $\alpha 5 \%=2,045$.

\section{Koefisien Determinasi}

\section{Model Summary}

\begin{tabular}{crrrrr}
\hline Model & $\mathrm{R}$ & R Square & $\begin{array}{c}\text { Adjusted R } \\
\text { Square }\end{array}$ & $\begin{array}{c}\text { Std. Error of the } \\
\text { Estimate }\end{array}$ & $\begin{array}{c}\text { Durbin } \\
\text { Watson }\end{array}$ \\
\hline 1 &, 725 &, 872 &, 625 & .4328 & 2,347 \\
\hline
\end{tabular}

a. Predictors (Constant), Budaya Organisasi

b. Dependent Variabel: Kepuasan kerja Karyawan

Diketahui nilai $\mathrm{R}=0,725$ menunjukkan bahwa budaya organisasi dan besarnya konpensasi memberi pengaruh yang signifikan terhadap kepuasan kerja karyawan. Berdasarkan nilai $\mathrm{R}^{2}=0,872$ atau $87,2 \%$ dinyatakan bahwa buadaya organisasi dan besarnya konpensasi memberi pengaruh yang kuat, sedangkan sisanya $12,8 \%(100 \%-87,2 \%)$ dipengaruhi oleh faktor lain yang tidak termasuk dalam penelitian ini.

\section{SIMPULAN DAN SARAN}

Simpulan

1. Hasil pengolahan data diperoleh nilai $t_{\text {hitung }}$ sebesar 4,271> nilai $>t_{\text {tabel }}$ pada $\alpha 5 \%$ sebesar 2,045 berarti $\mathrm{H}_{1}$ diterima, maka dapat disimpulkan budaya organisasi memberi pengaruh yang signifikan terhadap kepuasan kerja karyawan.

2. Hasil pengolahan data diperoleh nilai $t_{\text {hitung }}$ sebesar $5,143>$ nilai $t_{\text {label }}$ pada $\alpha 5 \%$ sebesar 2,045 berarti $\mathrm{H}_{1}$ diterma, maka dapat disimpulkan bahwa besarnya kompensasi memberi pengaruh yang signifikan terhadap kepuasan kerja karyawan.

3. Hasil pengolahan data diperoleh nilai koefisien determinasi $\left(\mathrm{R}^{2}\right)$ sebesar 0,872 atau $87,2 \%$, ini berarti budaya organisasi dan besarnya kompensasi secara bersama sama memberi pengaruh yang signifikan terhadap kepuasan kerja karyawan. Dan sebanyak $12,8 \%(100 \%-87,2 \%)$ yang tidak dianalisis dalam penelitian ini.

Saran

1. Budaya organisasi perlu ditingkatkan agar tujuan perusahaan dapat tercapai dengan baik.

2. Besarnya kompensasi yang diterima karyawan perlu ditinjau kembali supaya karyawan dapat termotivasi dalam melaksanakan tugasnya.

3. Untuk meningkatkan kinerja karyawan pasilitas kerja perlu dilengkapi sesuai kebutuhan.

\section{DAFTAR PUSTAKA}

As'ad,M.(2002). Psikologi Industri. Liberti: Yogyakarta.

Cusway.(2002). Penilaian Kinerja dan Pengembangan Karyawan.Gadjah Mada University Press:Yogyakarta.

Davis, Keith, and Newstron,W.John,(1993). Perilaku dalam Organisasi. Erlangga: Jakarta. 
Desler, Garry.(2000).Manajemen Sumber Daya Manusia. Prenhalindo: Jakarta.

Flippo,E.B.(2000).Manajemen Personalia. Erlangga: Jakarta.

Gibson and Donnelly,(2000).Behavior in Organizations. Prentice Hall International Inc: New York.

Handoko,T.Hani,(2001).Manajemen Personalia dan Sumber Daya Manusia. BPFE Universitas Gadjah Mada : Yogyakarta

Husnan Suad. (2000).Perilaku Konsumen. Andi : Yogyakarta.

Koentjaraningrat.(2002).PengantarAntropologi. Rineka Cipta: Jakarta.

Kotler, Philip, (1994). Manajemen Pemasaran. Erlangga: Jakarta.

Luthans and Fred, (1995).Organization Behavior.Publisher:McGraw-Hill ;NewYork.

Mondy, R. Wayne dan Premeaux R. Shane.(1993).Managemen : Consepts, Practices and Skills. Allyn \& Bacon, Incorporate: Singapura.

Muhlis M, (2002). Perilaku organisasi. Universitas Gadjah Mada: Yogyakarta.

Moorhead, G. and Griffin, R.W. 1999. Organizational Behavior: Managing People and Organizations.Houghton Mifflin : Boston.

Martoyo, Susilo.(1990). Manajemen Sumber Daya Manusia. BPFE Universitas Gadjah Mada: Yogyakarta.

Neale, GB and Norteraf,MA.(1998). Organizational Behavior: A Management
Challenge. The Dryden: Boston.

Prawirosentoso, S.(2001).Manajemen Sumber Daya Manusia Kebijakan Kinerja Karyawan. BPFE: Yogyakarta.

Robbins, Stepen P, (2001). Organization Theory: Structure, Design, and Aplication. Prentice Hall: New York.

Randolph, W. Alan, and Blackburn, S. Richard.(1989).Managing Organization Behavior. Houghton Mifflin : Boston.

Shein S. (1985). organizational Behavior: Concepts,Controversies and Aplication. Prentice Hall International Inc: San Diego.

Siagian, Sondang P. (2002). Kiat Meningkatkan Produktivitas Kerja. Rineka Cipta:Jakarta

Suprihanto, John. (2000). Penilaian Kinerja dan Pengembangan Karyawan. Gadjah Mada University Press: Yogyakarta.

Stoner, James A, F and R. Edward Freeman. (2000).Management.Prentice-Hall International: New Jersey.

Tan, V.(2002).Changing Your Corporate Culture. Time Books International:Singapore.

Winardi.(2000). Manajemen Pemasaran. Angkasa Raya: Bandung.

Wibowo.(2006). Budaya dan Iklim Organisasi. Salemba Empat: Jakarta.

Whitmore, J.(2000).Coaching For Performance, Seni Mengarahkan Untuk Mendongkrak Kinerja. Gramedia Pustaka Utama: Jakarta. 